\title{
Disseminating Innovation and Entrepreneurship Initiatives throughout a STEM- Focused Campus: An Agile Experience
}

\section{Prof. Jenifer Blacklock, Colorado School of Mines}

Dr. Jenifer Blacklock is the Assistant Department Head in the Mechanical Engineering department at Colorado School of Mines. Jenifer is active in the Undergraduate Curriculum in the Mechanical Engineering department and is an advocate of using hands-on-learning tools to help develop strong math, science and engineering foundations.

\section{Prof. Mark B. Mondry, Colorado School of Mines}

Mark B. Mondry is the Director of the Engineering \& Technology Management Program and a Teaching Associate Professor at the Colorado School of Mines in Golden, Colorado. 


\title{
Disseminating Innovation and Entrepreneurship Initiatives throughout a STEM Focused Campus - An Agile Experience
}

\begin{abstract}
Colorado School of Mines is a top public research university focusing on the STEM disciplines, with rigorous academics and a culture that encourages students to make a positive impact on our world. There is an undeniable thrust across engineering education to propel innovation and entrepreneurship throughout the undergraduate student experience, and it applies to our institution. In the fall of 2015, a small team of faculty and one student initiated a ambitious effort to build an ecosystem of innovation and entrepreneurship at Colorado School of Mines from the grassroots level using an agile approach of learning, doing, and iterating. This agile approach quickly created a critical-mass of activities, involvement and support. Remarkably, within one academic year, the effort successfully cultivated a vibrant and growing culture of innovation and entrepreneurship across the university's community of students, faculty and staff.
\end{abstract}

The journey continues, but this paper describes the approach and activities applied to generate this new culture in a traditional STEM focused campus.

\section{Applying Agile, Lean and Design Thinking}

Across many engineering programs in higher education, there is a wave of energy focused on learning-by-doing and human-centered design. From the business and engineering domains, students are being introduced to the concepts of Lean and Agile to inspire new ways of accomplishing collaborative, team oriented projects that require rapid iteration towards solutions for open-ended problems. A significant portion of STEM Faculty spends a great deal of time and energy incorporating these concepts into effective pedagogy applied to undergraduate engineering education. Often, these same faculty members are eagerly engaged in advancing the entrepreneurial learning ecosystem in their institutions. In engineering and other STEM programs, we apply innovation and entrepreneurship as the catalysts used to help guide students into the learning experiences and outcomes that represent the skills and knowledge they will need to succeed in their careers. ${ }^{1}$

Yet, these efforts do not come naturally in many of the university ecosystems. In many more traditional engineering programs, these same agile and lean approaches, not to mention the concept of design thinking ${ }^{2}$, fail to get incorporated into the improvement process for curriculum, co-curriculum and program development.

\section{The Grassroots Efforts}

At Colorado School of Mines, it all started with a comment from a prospective student and an inquiry from a non-traditional undergraduate who was looking for something outside of the 
traditional engineering curriculum: innovation and entrepreneurship. The prospective student innocently stated, "Why would I go to Colorado School of Mines? I want to be an entrepreneur" and the non-traditional student inquired about "courses that will make me be a better innovator". It took one ambitious faculty member to hear these statements and to gather a team comprising three other like-minded faculty members who shared the belief that Colorado School of Mines had an opportunity to positively change the innovation and entrepreneurship ecosystem at Their institution. The quest for support began.

Epicenter, started through Stanford University as a product of a NSF grant, launched a program called the Pathways to Innovation Program ${ }^{3}$ ("Pathways") in 2014. The Pathways program provided support for three separate annual cohorts of institutions to amplify innovation and entrepreneurship in engineering education. ${ }^{4}$ Colorado School of Mines applied to be a Pathways institution, and was selected in early 2015. Becoming a Pathways institution allowed the faculty members to participate as formal a team on campus. Becoming a Pathways team provided also provided a vehicle to coordinate activities and initiatives. The team first gathered at a planning conference with other newly minted Pathways institution teams that February. The purpose of the conference was for each team to begin to formulate a plan of action for amplifying innovation and entrepreneurship at their institution and to identify an initial project for their institutional team to take back with them and execute on.

The process each team was requested to adopt was called "Strategic Doing" as developed by a Center at Purdue University. ${ }^{5}$ The process is uniquely suited for higher education and incorporates a monthly strategy review and progress report. This process set a monthly clockspeed of progress capture and reporting for each team. Additionally, each team was partnered with several other Pathways teams from other institutions with a monthly check-in video meeting to share progress, issues and advice. The process began and the clock started to tick.

\section{Agile Development of a Vision and Resources}

The Strategic Doing process offered a wonderful framework for formulating a strategic roadmap of what projects and activities our team wanted to work on while keeping in mind, feasibility at the university level. Our team first mapped the current state of innovation and entrepreneurship on campus, including any student activities, resources, courses, or other relevant elements of our campus community. We instituted a weekly team meeting using an agile development methodology. ${ }^{6}$

In a commercial organization, the rapid pace of activity associated with an agile project management process is well tolerated, but in an academic institution, it can be a challenge to apply successfully. Scheduling weekly meetings requiring consistent and regular attendance by academics was the first challenge. Each week, we would review progress and accomplishments from the week before, discuss and agree on a set of activities for the approaching week, and discuss any foreseeable obstacles in our immediate path. It is not unusual for STEM faculty to incorporate agile processes in engineering course content, but this was truly learning by doing for some members of our team. The team, by the way, began to grow. As we communicated 
and gathered information from faculty colleagues on campus, more like-minded individuals began to engage who shared our vision.

\section{Iterate, iterate and Celebrate Small Victories}

Our team's initial project involved an application of design thinking to our process. Simplified, the general design thinking approach we embraced was to empathize, define, ideate, iterate and launch. We started with our search for empathy.

Each team member talked with many members of our academic community, students, faculty administration and staff, to find out how they viewed the current state and desirability of innovation and entrepreneurship on our campus. Our goal was to gain empathy for the people who would engage with the activities and resources we sought to create. How did students "innovate" things on campus? How many student entrepreneurs were actively working on startups? What resources were available and how were they used? Each of these questions facilitated new learning for the team and new insight on how to define our evolving objectives and projects.

By analyzing the current state (2015) of Colorado School of Mines and discussing what was being done well and not so well at the time, we were able to define a feasible plan forward for our one-year objectives. This became our baseline for progress subject to new learning and continuous iteration. Our extensive interviews illuminated one simple truth: students who might be interested in gathering around an idea for a new technology or in actually forming a startup did not have a clearly identified central source of information to learn about resources available on campus and in our nearby community. Thus, the team decided to develop a digital hub that could become the dynamic collection point for this kind of information and made available to the entire community at Colorado School of Mines. This hub would provide links to Colorado School of Mines courses, research efforts, student clubs, campus facilities, and external resources like regional seminars, professional groups, startup competitions, and incubators and accelerator programs. ${ }^{7}$

Next, the team explored how innovation and entrepreneurship could be provided as a continuum across all four years of a typical undergraduate journey at Colorado School of Mines. Our initial mapping efforts provided a clear understanding of what resources where currently available, now our team focused on filling the gaps. In our weekly meetings and monthly cohort updates, we tracked progress, iterations and challenges.

\section{What has Worked?}

As a direct result of our Pathways team efforts, there have been a handful of new innovation and entrepreneurship initiatives on campus. These initiatives have been driven by students, faculty and Colorado School of Mines college Deans within the past year, and all have helped lead to the success of creating an innovation and entrepreneurship mindset on campus. 
Student led efforts have included the creation of new student clubs and organizations. Examples include the Colorado School of Mines Maker Society, a hackers club, a rejuvenated student Entrepreneur Club, new hack-a-thons, a new freshman residential learning community based on the ASE Grand Challenges in Engineering. ${ }^{8}$ Faculty led efforts have so far culminated into a new entrepreneurship course for undergraduates, a campus-wide student innovation competition supported by significant corporate sponsored financial and other resources, and a new makerspace for students. Faculty and students have worked together to also develop and launch numerous video training resources on the Colorado School of Mines digital hub. Collectively, all these new innovation and entrepreneurship activities reflect an astounding success in only one year.

\section{What Has Not Worked?}

Although our institution has progressed significantly in implementing an innovation and entrepreneurship mindset on campus, it is currently still a challenge to get more faculty on-board and integrated with these initiatives. Two faculty members of our Pathways team hosted an Innovation Faculty Forum on campus, trying to gather like-minded faculty from across campus together to discuss the many efforts being deployed on campus. The forum was not well attended. There were high hopes of bringing faculty together under our renewed enthusiasm, but that is not what happened.

In trying to better understand the challenges associated with broadening our team's efforts, we have encountered a common theme. It is called formal recognition, or rather the perception that these efforts will not be recognized as important to faculty promotion and tenure. Research faculty in particular does not see how efforts in this area will be professionally rewarded. In our institution, we have a strong foundation in undergraduate teaching. Each faculty member is on one of two formal tracks: tenure track research faculty or formal teaching faculty. Each track has the same three levels of Assistant Professor, Associate professor and full Professor. Not surprisingly, our Pathways team led by a teaching tack faculty member and the team is comprised of mostly teaching track faculty.

\section{The Need and Assessment of the Current Landscape}

Students from across campus were asked about their desires and needs for Innovation and Entrepreneurial initiatives at Mines (IRB approved study). At a student-focused university, students have the ability to lead efforts on campus and assist in helping with campus initiatives and strategic plans. 75 students from across campus completed the survey and the results show that there is significant interest for innovation and entrepreneurship on campus and that students want to see workshops and several more courses integrated within both the curriculum as well as campus. Additionally, students wanted to see skills and concepts related to Innovation and Entrepreneurship throughout courses in the curriculum. 
Results from student survey (77 responses):

1) While at Colorado School of Mines, have you ever had an idea that you wanted to explore?

\begin{tabular}{|l|l|}
\hline yes & $90 \%$ \\
\hline no & $10 \%$ \\
\hline
\end{tabular}

2) While at Colorado School of Mines, were you ever engaged in Innovation and/or Entrepreneurial initiatives on campus such as a club, extracurricular activity, class, competition?

\begin{tabular}{|l|l|}
\hline yes & $\mathbf{6 0} \%$ \\
\hline no & $40 \%$ \\
\hline
\end{tabular}

3) Do you think you would ever consider being an entrepreneur within 10 years after graduation?

\begin{tabular}{|l|l|}
\hline yes & $72 \%$ \\
\hline no & $28 \%$ \\
\hline
\end{tabular}

4) Do you wish there were more Innovation and/or Entrepreneurial initiatives at Colorado School of Mines?

\begin{tabular}{|l|l|}
\hline yes & $75.68 \%$ \\
\hline no & $24.32 \%$ \\
\hline
\end{tabular}

5) What Innovation and/or Entrepreneurial initiatives do you wish there were more of at CSM? (open response)

\begin{tabular}{|l|l|}
\hline More business and I\&E focused courses & $\mathbf{2 6 . 3 1 \%}$ \\
\hline Workshops focused on I\&E & $21.05 \%$ \\
\hline Innovation Competitions with Prizes & $15.79 \%$ \\
\hline Concepts related to I\&E throughout curriculum & $15.79 \%$ \\
\hline
\end{tabular}

These results show that there is a strong need from students on campus for Innovation and Entrepreneurship, not just support, but for these skills to be found throughout the curriculum. Additionally, it was surprising to see the results from question 3, asking students whether or not they would ever consider being an entrepreneur within 10 years after graduation. Over $70 \%$ of the students surveyed responded with, 'yes', also emphasizing the need to implement more Innovation and Entrepreneurial initiatives on campus. Additionally, it is found that a large percentage (over 59\%) of students are engaged with the innovation and entrepreneurship efforts and initiatives currently on-campus, with many of these efforts beginning only a year ago. 


\section{Steps Forward}

Through this process, we have learned to continue to iterate. Our Pathways team has moved into a less formal schedule and works now on more of a project-by-project basis. Fortunately, innovation and entrepreneurship is now starting to be part of Colorado School of Mines culture.

However, there are still several foreseeable steps forward, particularly in the next six months. First off, we are continuously updating the HUB website with projects, innovation competitions (locally, nationally and at the campus and college level), new courses, training tutorials, along with pictures and images. Within the next couple of months, one of our major goals is to fully populate the site. To date, we have launched and maintained the site with no financial or formal support resources. The effort was completely the result of faculty and student grassroots efforts.

Additionally, our first campus-wide innovation competition will conclude at the end of the current semester. We will work on establishing this competition on an annual basis and work to launch a technology startup competition as well. Significant work will be needed to establish external sponsors, startup team mentors and other resources. We will continue to iterate and learn from our students on what activities are working, what can be improved, and how. As of this writing, we are also working with the city in our community to launch a local startup showcase and a local accelerator.

\section{Conclusion}

Many lessons have been learned throughout this process, however, the strongest message we have taken away from the past year is that innovation and entrepreneurship can be integrated into a culture, quickly and efficiently, by applying the same principles and concepts we are teaching our students to make them stronger innovators and entrepreneurs. These concepts are being heard around campuses alike, however various approaches are being applied to the delivery, some successful, some not so successful. We have seen positive results by empathizing, defining, ideating, iterating and launching innovation and entrepreneurship initiatives Colorado School of Mines. 


\section{References}

1.) Nathalie Duval-Couetil; Michael J. Dyrenfurth (2015), "Teaching Students to be Technology Innovators: Examining Approaches and Identifying Competencies," https://pathways.epicenterusa.org/resources/561.

2.) Design Thinking has been defined many ways, but for the purposes of this paper we shall define it generally as a design-inspired approach to framing and solving problems from a empathy-based, humanistic perspective. See generally, N. Cross, Design Thinking, Berg 2011, and T. Brown, Change By Design, Harper Business, 2009.

3.) The Pathways to Innovation Program is a part of Epicenter, managed by Stanford University and Venturewell. Epicenter is a broad institutional change effort to embed innovation and entrepreneurship into undergraduate engineering education (Epicenter NSF STEP Award \#1125457). More information can be found at http://epicenter.stanford.edu/. The original NSF grant that created Epicenter will expire in 2016.

4.) The three cohorts launched in 2014, 2015 and 2016 respectively.

5.) As described on the Strategic doing website (Strategicdoing.net), "Strategic Doing is a strategy discipline specifically designed for open, loosely-connected networks. Unlike strategic planning that was designed primarily to guide strategic activity in hierarchical organizations, Strategic Doing is designed for situations in which nobody can tell anybody else what to do. Collaboration is the only way to move forward." The approach was developed at the Purdue University Center for Regional Development.

6.) The concepts of Agile software development are now widely used for broad applications of product and service development as well as project management. J. Highsmith, Agile Project Management: Creating Innovative Products, $2^{\text {nd }}$ Ed., Addision-Wesley Professional, 2009.

7.) The hub concept has been embodied as the COLORADO SCHOOL OF MINES idea hub, called (omitted) that can be found at http:/www.midea.mines.edu.

8.) The National Academy of Engineering Grand Challenges for Engineering project is sponsored by a grant from the National Science Foundation. The Grand Challenges are a set of fourteen technical challenges for the $21^{\text {st }}$ century having significant opportunity to positively impact quality of life. The specific challenges were identified from collecting input from experts in science and engineering as well as the broader general public. The project also includes a grand Challenges Scholars Program, a program designed to advance engineering education and equip students to achieve the distinction of being a Grand Challenges Scholar. See http://www.grandchallenges.org. 